\title{
Breeding populations of Bombina orientalis Boulenger, 1890 (Amphibia Anura Bombinatoridae), in a degraded urban habitat in Vladivostok, Russia
}

\author{
Irina V. Maslova"*, Elvira E. Rodina², Yikweon Jang ${ }^{3}$ \& Amaël Borzée ${ }^{3 *}$ \\ ${ }^{1}$ Federal Scientific Center of the East Asia Terrestrial Biodiversity Far Eastern Branch of Russian Academy of Sciences, Vladivostok, \\ 690022, Russia \\ ${ }^{2}$ School of Natural Sciences, Far Eastern Federal University, Vladivostok 690090, Russia \\ ${ }^{3}$ Department of Life Sciences and Division of EcoScience, Ewha Womans University, Seoul, 03760, Republic of Korea \\ "Corresponding authors, e-mail: irinarana@yandex.ru; amaelborzee@gmail.com
}

\begin{abstract}
Most amphibian species are declining, and while the causes of such decline are multiple, environmental pollution is one of the most important. Bombina orientalis Boulenger, 1890 (Amphibia Anura Bombinatoridae), is known to be sensitive to pollution. However, we report here that the species breeds in highly polluted water within the city of Vladivostok, Russia. The species was found at the same site for two consecutive years, although in lower numbers in the second year. The resilience of $B$. orientalis to pollution is not consistent with other populations within the range of the species, and is therefore important in the frame of conservation.
\end{abstract}

KEY WORDS Bombina orientalis; breeding habitat; urbanisation; degraded habitat; Russia.

Received 20.03.2018; accepted 19.05.2018; printed 30.06.2018; published online 05.07.2018

\section{INTRODUCTION}

Amphibian (Amphibia Anura) populations are on the decline (Stuart et al., 2004; Pimm et al., 2014), and cities or urban areas are principally devoid of their presence. Most amphibian species require pristine and well connected habitats (Collins $\&$ Storfer, 2003; Becker et al., 2007), and are not present in ecologically disturbed areas.

This is, for instance, the case of the Rana Linnaeus, 1758 (Amphibia Anura Ranidae), species in North America, the genus with the highest number of negative responses to urban habitats (Scheffers \& Paszkowski, 2012). Only a few species are able to withstand the degraded ecological conditions of cities or urban areas as well as Duttaphrynus melanostictus (Schneider, 1799) (Bufonidae), a species commonly found in degraded areas and cities (Holzer et al., 2017).

One of the problems of urbanised areas is the high degree of pollution, besides the absence of adequate habitat, as environmental contamination negatively impacts amphibian populations (Sparling et al., 2010; Egea-Serrano et al., 2012). The effects of pollution are multiple, and resulted for instance in the decline of Acris crepitans Baird, 1854 (Hylidae) (Reeder et al., 2005), and in the absence of Dryophytes suweonensis (Kuramoto, 1980) (Hylidae) at sites with high pollution levels (Borzée et al., 2018).

Bombina orientalis Boulenger, 1890 (Bombinatoridae), the Oriental fire-bellied toad, is a species ranging from the Korean and Shandong peninsulas in the South to about $125^{\circ}$ North in China. Is it how- 
ever common in Primorsky Territory in Russia up to $135^{\circ} \mathrm{N}$, and present in small isolated groups in Khabarovsk Territory, up to $136^{\circ} \mathrm{N}$. Bombina orientalis is monophyletic within its range, despite local genetic and morphological variations (Kuzmin et al., 2010; Fong et al., 2016), with two morphological forms described in Primorsky Territory, Russia (Korotkov, 1972). The mostly terrestrial variety "sylvatica" is usually associated with forest habitats and never present in open wetlands further than $200 \mathrm{~m}$ from the forest border (Kuzmin \& Maslova, 2005), while the aquatic variety "praticola" is only recorded in sedge and reed meadows when associated with grasslands (Korotkov, 1972). The species is known to be sensitive to environmental pollutants due to abnormal development when close to human activities (Kang et al., 2016) and failure of embryonic development in polluted waters (Park et al., 2014). The species is common in forested zones around Vladivostok, Russia (Kuzmin \& Maslova, 2005), but was not expected to be present within the city due to habitat disconnection and heavy pollution (Vshivkova et al., 2014 ; Vshivkova, 2016; Maslova et al., 2016). It should, however, be noted that $B$. orientalis was observed in some forested parts of the city about 100 years ago; when the city was c. 50 year old (Kuzmin \& Maslova, 2005). The situation deteriorated in the 1950 s and 1960s, when the city was actively built up, especially in the focal areas of this study. This study aim at documenting the continued breeding activity of $B$. orientalis in polluted areas, within the city of Vladivostok.

\section{MATERIAL AND METHODS}

Vladivostok is situated on the MuravyovAmursky Peninsula, surrounded by the Sea of Japan and was originally completely covered by forests of cedar and broadleaved trees (Avdeev, 2015). Because of the peninsular location of the city, all urban streams are, at present, isolated from natural biotopes and are heavily polluted, following the industrial development of the city. Only Rana $d y$ bowskii Günther, 1876 (Ranidae), was known to occur within the northern part of the city, although several amphibian species are present in small isolated populations on its outskirts, including $B$. orientalis (Maslova et al., 2016). The study area, Cape
Firsov, is sandwiched between the city and the coastal line, preserved because of a railway, and mainly used for housing, warehouses, landfills, and wastelands (Fig. 1). The vegetation of the area is composed of individual willows and elms. A pond is present in the area, used for landfills and sewages dump.

\section{Surveys and data analysis}

We conducted aural and visual surveyed in Cape Firsov on 17 May 2016 to assess for the presence of $B$. orientalis. We annotated abiotic variables, vegetation, and pollution status at the site during the survey. To assess the presence of a breeding population, we conducted the same surveys on 27 April 2017 and again on 4, 18, and 19 August 2017 and annotated the presence of adult and juvenile amphibians present at the site. Environmental pollutants were also recorded by types. Our data subsequently qualitatively analysed the occurrence of the focal species and environmental pollutants.

\section{RESULTS}

Here, we report the first observation of $B$. orientalis within the city of Vladivostok, surviving in a highly polluted environment, and completely isolated from other populations. The first survey on 17 May 2016 resulted in the detection of multiple calling individuals (air temperature $=19.3{ }^{\circ} \mathrm{C}$ ) within plastic bags in a ditch located 80 meters east of the pond and 200 meters from the shore (Fig. 1). The ditch was littered with rubbish, mostly plastic bottle and bags, but also other heavy household wastes, and covered by herbaceous vegetation, with maximum water depth of $30 \mathrm{~cm}$ (Fig. 2). An individual was helped out of a bag to visually confirm the species.

Bombina orientalis was detected during the surveys conducted in 2017 to confirm the continuous presence of the species at the site over years, although seemingly impacted by local conditions. On 27 April 2017, no individuals were found: the ditch were the individuals were found the year before was dry. The trash included plastic bags and bottles, as in 2016, but also tyres and heavy metal parts. Besides, the dump had been used for burning, and the ground was scorched around the ditch (Fig. 3). Two adults were detected at the pond, despite the pol- 

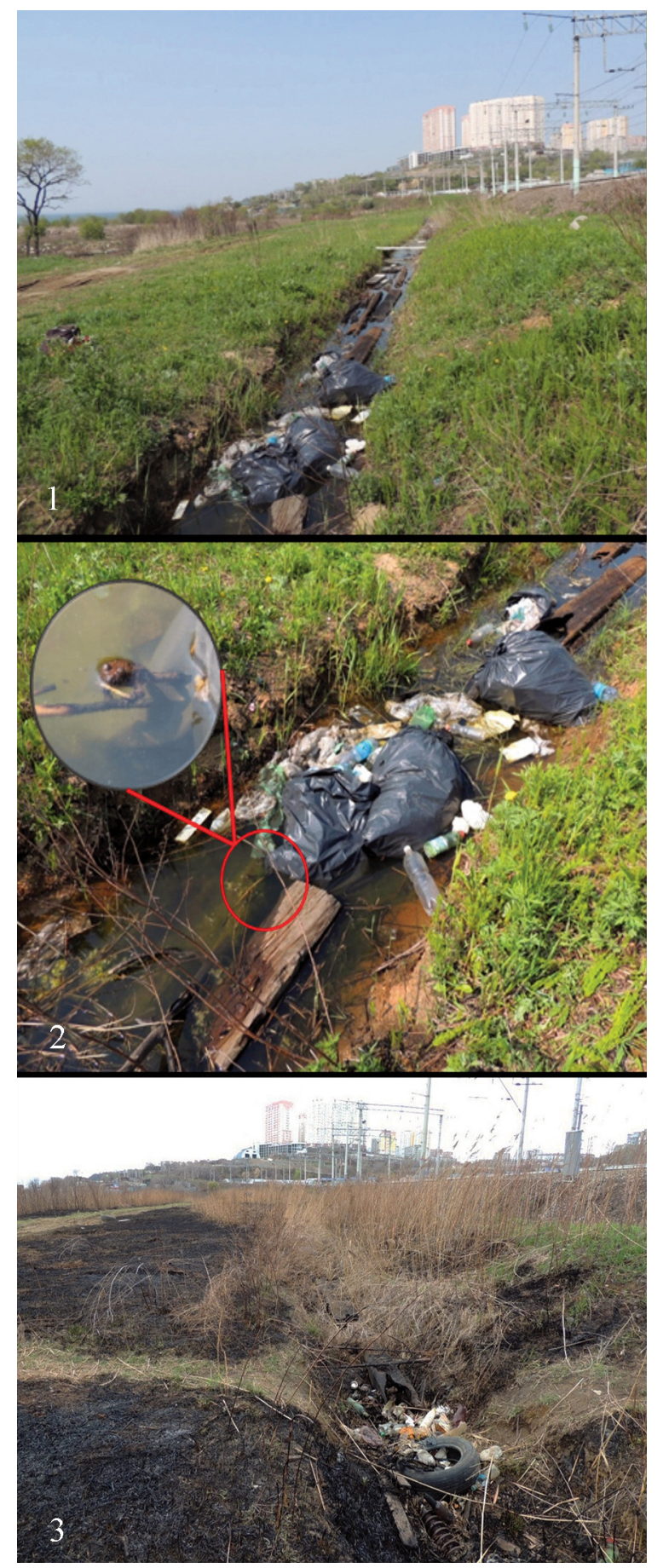

Figures 1,2. Site where Bombina orientalis was found breeding in Vladivostok in 2016. The site is isolated from other populations by the sea on three sides, and the city on the other one.

Figure 3. Site where Bombina orientalis was found breeding in Vladivostok, Russia, in 2016. The same type of trash was found in 2016 and 2017, with the addition of tyres and heavy machinery parts in 2017. Besides, the dump site had been burnt in 2017. luted conditions, on 4 August 2017, a single juvenile was found in the vicinity of the pond on $18 \mathrm{Au}$ gust 2017, and finally, two adults and one juvenile were found on 19 August 2017, at the same location. The presence of juveniles highlights the breeding activity of $B$. orientalis at the site, despite the heavy pollution.

When comparing for the type of environmental pollution, the sewage dump was the same at the pond in 2016 and 2017, but we did not detect the species in the pond in 2016. The land pollution mostly comprised plastic items in 2016 and 2017, with the addition of burnt items and tyres plus heavy machinery parts in 2017 . The species was found breeding in the ditch in 2016 only.

\section{DISCUSSION AND CONCLUSIONS}

Our observations first demonstrate the presence of $B$. orientalis within the city of Vladivostok in Russia. We also demonstrate that the species can breed, at an unknown fitness cost, in highly polluted and disturbed conditions. These observations therefore hint at an unexpectedly high ecological plasticity in B. orientalis. Furthermore, based on the presence of morphological abnormalities close to cities (Kang et al., 2016), we could have expected individuals with additional or missing limbs, which was not the case. We expect the hatching and development rate of individuals breeding in the pond to be significantly lower, as Park et al. (2014) reported the failure of embryonic development in polluted waters. Finally, we hypothesise that calling individuals found in 2016 were in the plastic bags as they would have provided a warmer environment, and may have potentially provided call amplifiers.

\section{ACKNOWLEDGEMENTS}

This work was partially supported by a grant from the National Research Foundation of Korea (2017R1A2B2003579) to YJ. These observation follow the laws of the Russian Federation.

\section{REFERENCES}

Avdeev Y.A., 2015. The Agglomeration is "Big Vladi- 
vostok". The Window in APR (The Window to the Asia-Pacific region) Political magazine the Far Eastern Federal District Vladivostok, Russia: Publishing house of "Vostok Rossii".

Becker C.G., Fonseca C.R., Haddad C.F.B., Batista R.F. \& Prado P.I., 2007. Habitat split and the global decline of amphibians. Science, 318: 1775-1777. DOI: 10.1126/science. 1149374

Borzée A., Kyong C.N., Kil H.K. \& Jang Y., 2018. Impact of water quality on the occurrence of two endangered Korean anurans: Dryophytes suweonensis and Pelophylax chosenicus. Herpetologica, 7: 1-7. DOI: 10.1655/Herpetologica-D-17-00011

Collins J.P. \& Storfer A., 2003. Global amphibian declines: sorting the hypotheses. Diversity and Distributions, 9: 89-98. DOI: org/10.1046/j.1472- 4642. 2003. 00012.x

Egea-Serrano A., Relyea R.A., Tejedo M. \& Torralva M., 2012. Understanding of the impact of chemicals on amphibians: a meta-analytic review. Ecology and Evolution, 2: 1382-1397. DOI: 10.1002/ece3.249

Fong J.J., Li P.-P., Yang B.-T., Zhou Z.-Y., Leaché A.D., Min M.-S. \& Waldman B., 2016. Influence of geology and human activity on the genetic structure and demography of the Oriental fire-bellied toad (Bombina orientalis). Molecular phylogenetics and Evolution, 97: 69-75. DOI: 10.1016/j.ympev.2015. 12. 019

Holzer K.A., Bayers R.P., Nguyen T.T. \& Lawler S.P., 2017. Habitat value of cities and rice paddies for amphibians in rapidly urbanizing Vietnam. Journal of Urban Ecology, 3: 1-12. DOI: 10.1093/jue/ juw007

Kang C., Shin Y., Kim Y.E., Moon J., Kang J.Y. \& Jang Y., 2016. The incidence of abnormalities in the firebellied toad, Bombina orientalis, in relation to nearby human activity. Journal of Ecology and Environment, 39: 11-16. DOI: 10.5141/ecoenv.2016.002

Korotkov Y.M., 1972. To the biology of Bombina orientalis, Agkistrodon blomhoffii and A. halis in Primorye Region. Novosibirsk, Russia: Zoologicheskie Problemy Sibiri.

Kuzmin S.L. \& Maslova I.V., 2005. Amphibians of the Russian Far East. Moscow, Russia: KMK.

Kuzmin S., Poyarkov N. \& Maslova I., 2010. On the variability of fire-bellied toads in the Far East. Moscow University Biological Sciences Bulletin, 65: 34-39.
Maslova I.V., Akulenko M.F. \& Zhestkov A.Y., 2016. About the Herpetofauna of the city of Vladivostok (Primorsky krai, Russia). Ecological Principles, 5: 91.

Park C.J., Ahn H.M., Cho S.C., Kim T.H., Oh J.M., Ahn H.K., Chun S.H. \& Gye M.C., 2014. Developmental toxicity of treated municipal wastewater effluent on Bombina orientalis (Amphibia: Anura) embryos. Environmental Toxicology and Chemistry, 33: 954-961.

Pimm S.L., Jenkins C.N., Abell R., Brooks T.M., Gittleman J.L., Joppa L.N., Raven P.H., Roberts C.M. \& Sexton J.O., 2014. The biodiversity of species and their rates of extinction, distribution, and protection. Science, 344: 987-997. DOI: 10.1126/science. 1246752.

Reeder A.L., Ruiz M.O., Pessier A., Brown L.E., Levengood J.M., Phillips C.A., Wheeler M.B., Warner R.E. \& Beasley V.R., 2005. Intersexuality and the cricket frog decline: historic and geographic trends. Environmental Health Perspectives, 113: 261-265.

Scheffers B.R. \& Paszkowski C.A., 2012. The effects of urbanization on North American amphibian species: identifying new directions for urban conservation. Urban Ecosystems, 15: 133-147. DOI: 10.1007/ s11252-011-0199-y

Sparling D.W., Linder G., Bishop C.A. \& Krest S., 2010. Ecotoxicology of amphibians and reptiles. Boca Raton, USA: CRC Press; Taylor \& Francis.

Stuart S.N., Chanson J.S., Cox N.A., Young B.E., Rodrigues A.S., Fischman D.L. \& Waller R.W., 2004. Status and trends of amphibian declines and extinctions worldwide. Science, 306: 1783-1786. DOI: 10.1126/ science. 1103538

Vshivkova T., 2016. Problems of urban streams pollution. Vladivostok, Russia: Publishing house of Vladivostok State University of Economics and Service.

Vshivkova T., Medvedeva L., Buzoleva L., Khristoforova N., Kovekovdova L., Polyakova N. \& Drozdov K., 2014. Bioassessment of Vladivostok city and its vicinities streams by the classic chemical and microbiological methods together with biological and nuclear magnetic spectroscopy (NMS) methods (Primorye, Russian Far East). 2nd Symposium of Benthological Society of Asia, June 5-7 2014; Busan, Republic of Korea, pp. 72-73. 